Editorial

Volume 1 Issue 1 - April 2016
JOJ Case Stud

Copyright $(\subset)$ All rights are reserved by Sherry Arvidson

\title{
Promoting Student Success in Academia and Practice
}

\author{
Sherry Arvidson \\ Faculty of Nursing, University of Regina, Canada
}

Submission: April 10, 2016; Published: April 18, 2016

*Corresponding author: Sherry Arvidson, University of Regina, Canada, Tel: 306-337-3164; 306-535-4129; Email: sherry.arvidson@uregina.ca

\section{Editorial}

Supporting students through learning to reach goals of success should be a priority for educators in all realms of academia. Encouraging participation, advocacy, accountability, and partnership development are excellent strategies to implement into research and scholarship activities. From professional involvement with students participatory experiences have led to engagement, recognition, and awareness of the building of partnerships essential for constructing knowledge.

Students should be assessed for prior learning and training. Challenging situations stimulate critical thinking and problemsolving techniques. If students are not exposed to new learning opportunities, they will soon lose interest and as a result learning will become stagnant. Students require a scaffolding approach of knowledge construction. The essence of scaffolding curriculum ensures students have an opportunity to construct and advance knowledge from one year to the next. The application of content relevant to the context of learning adds to the ease of fostering student success.

Reflecting on a recent study that was part of my doctoral dissertation has marked emphasis on the development of critical thinking and cultural competency in learning. Choosing teaching strategies that suit the needs of the learner is important in successful learning. Specific to academia, educators need to focus on teaching strategies and methodology that align with course objectives. Assessment and evaluation of learning should be ongoing. Methods of teaching and strategies for content delivery need to fit the needs of the learner.

Students require appropriate areas of practice to enhance learning and want challenging situations to stay motivated and engaged. When the practice areas do not meet the learning needs of the students, a limited amount of knowledge construction takes place. As educators, we have roles and responsibilities to follow that will allow students to reach their maximum potential. Open communication, clear objectives, and constructive feedback allows for students to form a sense of trust and the development of academic integrity in the classroom. Appreciation of mutual respect and the desire to cultivate an environment conducive for learning is a win-win situation for both student and educator.

Instilling group norms and a visionary approach for learning provides a framework for the development of student success. Setting measurable and realistic goals within an achievable timeframe provides structure for task completion. Student involvement in leadership roles promotes the development of personal satisfaction and professional achievement. Immersing students in scholarship and research activities will take the level of learning to new heights. Embrace the importance of learning opportunities that support students to develop critical thinking and the required competency to excel. Enjoy your passion for teaching and support for student success. 